\title{
Deteksi Diabetik Retinopati menggunakan Regresi Logistik
}

\author{
Raras Tyasnurita ${ }^{\mathrm{a}, 1, *}$ dan Adhi Yoga Muris Pamungkas ${ }^{\mathrm{a}, 2}$ \\ ${ }^{a}$ Departemen Sistem Informasi, Fakultas Teknologi Elektro dan Informatika Cerdas, Institut Teknologi Sepuluh \\ Nopember Surabaya Indonesia 60111 \\ ${ }^{1}$ raras@is.its.ac.id; ${ }^{2}$ yogamuris@gmail.com \\ *corresponding author
}

\begin{abstract}
INFORMASI ARTIKEL ABSTRAK
Diterima : 19 Juni 2020

$\begin{array}{ll}\text { Diterima } & 19 \text { Juni } 2020 \\ \text { Diulas } & \text { : } 18 \text { Juli } 2020\end{array}$

Direvisi : 22 Juli 2020

Diterbitkan : 27 Agustus 2020

Kata Kunci:

Diabetik retinopati

Regresi logistik

Klasifikasi

Pembelajaran mesin

Diabetik retinopati adalah penyakit yang diakibatkan oleh komplikasi dari diabetes melitus yang dapat menyebabkan kerusakan pada retina mata. Kondisi ini akan mengganggu penglihatan pada penderita. Mendeteksi penyakit ini sangat penting dilakukan untuk mencegah kebutaan total pada penderita diabetes melitus. Salah satu metode deteksi adalah dengan menggunakan pembelajaran mesin. Penelitian ini menggunakan data ekstraksi fitur dari citra mata yang terdapat tanda-tanda diabetik retinopati atau tidak. Fokus penelitian ini adalah klasifikasi data penderita diabetik retinopati. Klasifikasi dilakukan dengan menggunakan algoritma regresi logistik. Terdapat empat macam kondisi pelatihan data pada model pembelajaran mesin yaitu dengan menggunakan parameter bawaan, standarisasi atribut, pemilihan atribut, dan pengaturan parameter. Model menggunakan nilai kontrol regularisasi (C) sebesar 11,288, nilai iterasi sebanyak 200, dan penalti regularisasi (11). Hasil dari eksperimen menunjukkan bahwa model tersebut dengan kondisi atribut lengkap menghasilkan akurasi sebesar $80,17 \%$ pada data validasi.
\end{abstract}

Keywords:

Retinopathy diabetic

Logistic regression

Classification

Machine learning

\section{ABSTRACT}

Retinopathy diabetic is a disease caused by diabetes mellitus complications that can cause damage to the retina of the eye. It has a direct impact on the disruption of the vision of the patient. Detecting this disease is very important to prevent total blindness on diabetes mellitus patients. One method to do the detection is by using machine learning. This research uses feature extraction data from an image that contains signs of retinopathy diabetic or not. In this research, we focus on retinopathy diabetic classification. We applied logistic regression algorithm for classification. There is four training condition in a machine learning model: using the default parameter, feature standardization, feature selection, and hyper-parameter tuning. The model used a regularization control (C) value of 11.288 , iterations 200 , and a regularization penalty (11). The experimental results show that this proposed model with full features produced $80,17 \%$ accuracy in data validation.

This is an open access article under the CC-BY-SA license.

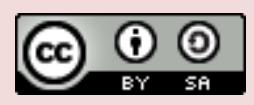

\section{Pendahuluan}

Diabetes melitus merupakan penyakit metabolik dimana penderita diabetes tidak bisa memproduksi insulin dalam jumlah cukup atau tubuh tidak mampu menggunakan insulin secara efektif sehingga terjadi kelebihan gula di dalam darah. Kondisi ini baru dirasakan setelah terjadi komplikasi lanjut pada organ tubuh. Pada penderita diabetes melitus, dapat terjadi komplikasi pada tingkat sel dan anatomik. Komplikasi kronik yang disebabkan oleh diabetes melitus dapat terjadi pada pembuluh darah besar (makrovaskuler) dan pembuluh darah kecil (mikrovaskuler). Komplikasi makrovaskuler yang umum terjadi adalah pembekuan darah pada otak, penyakit jantung koroner, dan stroke. Sedangkan komplikasi mikrovaskuler yang umum terjadi adalah hiperglikemia dan retinopati (kebutaan) [1].

Retinopati diabetik merupakan kerusakan retina yang diakibatkan oleh komplikasi dari diabetes melitus [2]. Menurut data dari WHO pada tahun 2015, Indonesia menempati posisi ke tujuh di dunia untuk prevalensi penderita diabetes tertinggi di dunia dengan estimasi penderita diabetes sebesar 10 juta orang dari jumlah penderita diabetes di dunia sebesar 415 juta jiwa. Berdasarkan penelitian yang dilakukan oleh 
Soewondo dkk (2010) [3], sebanyak 42\% dari 1785 penderita diabetes melitus di Indonesia mengalami komplikasi retinopati diabetes.

Pembelajaran mesin (machine learning) dapat didefinisikan sebagai proses dimana sistem dapat meningkatkan performa dari pengalaman. Terdapat tiga jenis machine learning yaitu supervised learning, unsupervised learning, dan reinforcement learning. Salah satu task dalam supervised learning adalah klasifikasi, dimana ini menjadi fokus permasalahan dari penelitian ini. Pada penelitian ini dibuat model machine learning untuk melakukan klasifikasi terhadap penyakit diabetik retinopati. Penelitian terbaru menunjukkan bahwa dari beberapa algoritma pembelajaran mesin, pengklasifikasi regresi logistik menghasilkan akurasi yang paling tinggi (77\%) dibanding dengan Random Forest (68\%), Decision Tree (55\%), Adaboost (67\%), dan K-Nearest Neighbour (65\%) [4]. Selain itu, penelitian sebelumnya menunjukkan bahwa regresi logistik lebih superior dibanding algoritma pembelajaran mesin yang lain dalam hal pemodelan prediksi klinis [5]. Penelitian ini bertujuan untuk melakukan klasifikasi mengenai kejadian diabetik retinopati. Prediksi dilakukan dengan menggunakan metode regresi logistik.

\section{Metode}

Machine Learning (Pembelajaran Mesin) memiliki peran penting dalam mengenali pola pada data seperti data kesehatan di masa serba digital ini. Herbert Simon mendefinisikan belajar sebagai proses dimana sistem dapat meningkatkan performa dari pengalaman [6]. Tom Mitchell mendefinisikan machine learning sebagai studi dari algoritma yang dapat meningkatkan performa $P$ pada aktivitas $T$ dengan pengalaman $E$ [7]. Machine learning terdiri dari tiga jenis yaitu supervised learning, unsupervised learning, dan reinforcement learning [8]. Supervised learning adalah sistem belajar dari data yang memiliki label, contoh dari supervised learning adalah klasifikasi. Unsupervised learning merupakan sistem belajar dari data yang tidak memiliki label, contohnya merupakan permasalahan klusterisasi. Sedangkan reinforcement learning merupakan sistem yang diberikan pada serangkaian aksi dengan reward, contoh dari reinforcement learning adalah permasalahan penilaian skor kredit pada bank.

Penelitian yang dilakukan penulis berfokus pada permasalahan klasifikasi dimana sistem akan melakukan klasifikasi apakah seseorang memiliki risiko diabetik retinopati atau tidak. Alur klasifikasi pada penelitian ini ditunjukkan pada Gambar 1 dimana terdiri dari 5 tahap [9] yaitu:

A. Pengumpulan data

Langkah pertama yang dilakukan adalah mengumpulkan data. Dataset yang digunakan diambil dari UCI Machine Learning [10]. Dataset yang diambil adalah data mengenai kejadian retinopati diabetik. Pada dataset terdapat ciri (feature) yang diekstrak dari dataset berupa gambar dari Messidor untuk memprediksi apakah pada gambar terdapat gejala retinopati diabetik atau tidak.

\section{B. Pemrosesan data}

Setelah data dikumpulkan, langkah selanjutnya adalah melakukan pengolahan terhadap data yang sudah dikumpulkan. Dataset memiliki jumlah baris sebanyak 1151 baris. Pengolahan data ini meliputi menghilangkan missing values yang ada dalam data. Pada dataset terdapat 20 atribut dengan rincian 19 atribut ciri dan 1 atribut label. Pada dataset dilakukan pembagian data menjadi data pelatihan sebanyak $90 \%$ dari keseluruhan data dan data validasi sebesar $10 \%$ dari keseluruhan data. Data pelatihan yang dihasilkan kemudian dilakukan pembagian data menjadi $70 \%$ sebagai data pelatihan dan $30 \%$ sebagai data pengujian.

\section{Pelatihan model}

Pelatihan model dilakukan dengan menggunakan tiga skenario. Skenario pertama yang digunakan adalah membuat base model dengan menggunakan keseluruhan variabel dari data. Skenario kedua adalah melakukan pemodelan dengan melakukan standarisasi pada data. Skenario ketiga adalah melakukan pemodelan dengan melakukan feature selection pada ciri (feature) dari data.

D. Evaluasi model

Setelah dilakukan pelatihan model, selanjutnya adalah mengevaluasi performa dari model tersebut. Evaluasi model ini meliputi tingkat akurasi model, presisi, recall, sensitivitas, dan F1 score [11]. Selain itu metode evaluasi menggunakan confusion matrix.

\section{E. Peningkatan performa}

Dari evaluasi model akan diketahui performa dari model. Terdapat beberapa teknik untuk meningkatkan performa dari model, diantaranya adalah hyper-parameter tuning [12]. Pada tahap peningkatan performa dilakukan penyetelan parameter atau hyper-parameter tuning pada metode logistik regresi. Parameter yang dilakukan penyetelan adalah parameter $\mathrm{C}$ (variabel kontrol yang mempertahankan modifikasi kekuatan regularisasi), iterasi maksimum (max_iter), dan penalti.

Regresi Logistik adalah metode statistik yang merupakan bagian dari analisis regresi yang biasanya digunakan untuk memprediksi kelas biner [13]. Variabel target bersifat dikotomi atau biner. Dikotomi berarti hanya terdiri atas dua kelas atau nilai, yang biasanya dituliskan dengan angka 1 (ya, sukses, dll) atau 0 (tidak, gagal, dll). Regresi logistik juga merupakan salah satu algoritma klasifikasi yang sering dipakai di dunia kesehatan [14]. Fungsi logistik disebut juga dengan Fungsi Sigmoid karena memberikan kurva berbentuk 'S' 
yang dapat mengambil bilangan real-value dan memetakannya menjadi nilai antara 0 dan 1 [8]. Kurva regresi logistik ditunjukkan pada Gambar 2. Jika kurva menuju infinity positif, nilai y (output) akan diprediksi menjadi 1, dan jika kurva pergi ke infinity negatif, nilai y (output) akan diprediksi menjadi 0. Jika output dari fungsi sigmoid lebih dari 0,5, kita dapat mengklasifikasikan hasilnya sebagai 1 atau YA, dan jika kurang dari 0,5, kita dapat mengklasifikasikannya sebagai 0 atau TIDAK.

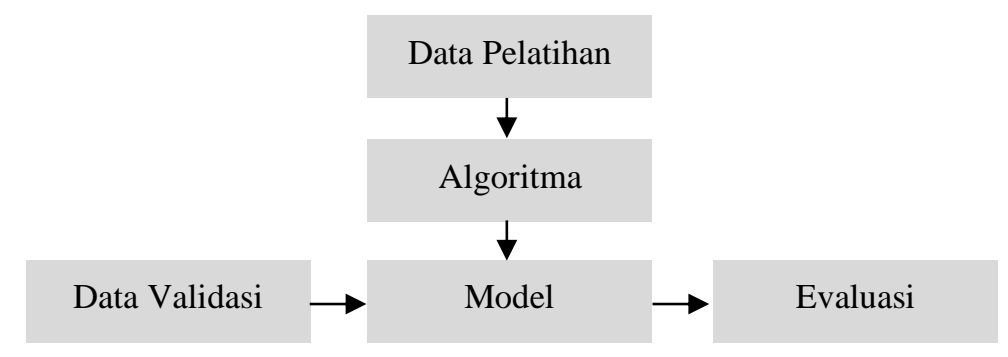

Gambar 1. Bagan alur klasifikasi pada machine learning

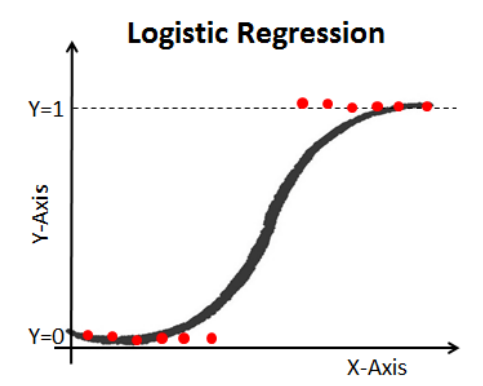

Gambar 2. Kurva Regresi logistik [15]

\section{Hasil dan Pembahasan}

Pada bagian ini diuraikan hasil dari model machine learning yang telah dibuat. Model dibuat dengan menggunakan bahasa Python melalui jupyter notebook.

A. Proses pelatihan model

Dataset terdiri dari 1151 baris data dan 20 atribut. Dari 1151 baris data tersebut dilakukan pembagian data dengan porsi sebanyak $90 \%$ untuk data pelatihan dan $10 \%$ untuk data validasi. Dari $90 \%$ data pelatihan kemudian dilakukan pembagian data sebagai data pelatihan dengan proporsi $70 \%$ dan data pengujian dengan proporsi sebesar 30\%. Model dibuat dengan menggunakan algoritma regresi logistik. Pada skenario pemodelan 1 (Model 1) dilakukan pemodelan dengan menggunakan parameter penalti 11 dan nilai $C$ sebesar 0.1. Parameter penalti (regularisasi 11) adalah sama dengan nilai absolut dari besarnya koefisien. Terdapat pula parameter penalti lain yaitu regularisasi 12 dimana nilainya sama dengan sama dengan kuadrat dari koefisien. Dari hasil pemodelan dengan menggunakan nilai parameter tersebut didapatkan hasil akurasi pada data pelatihan sebesar $75,96 \%$ dan akurasi pada data pengujian sebesar $75,24 \%$. Selanjutnya dilakukan tes terhadap data validasi sebesar $10 \%$ dari total baris data. Tabel 1 menunjukkan hasil tes terhadap data validasi dimana didapatkan hasil akurasi sebesar 78,45\%. Confusion matrix dari model 1 dapat dilihat pada Tabel 2 dimana detail analisis statistik dirangkum pada Tabel 3.

Tabel 1. Performa Model 1

\begin{tabular}{cccc} 
Model & $\begin{array}{c}\text { Akurasi Data } \\
\text { Pelatihan }\end{array}$ & $\begin{array}{c}\text { Akurasi Data } \\
\text { Pengujian }\end{array}$ & $\begin{array}{c}\text { Akurasi Data } \\
\text { Validasi }\end{array}$ \\
\hline Model 1 & $75,96 \%$ & $75,24 \%$ & $78,45 \%$ \\
\hline
\end{tabular}

Tabel 2. Confusion Matrix Model 1 pada Data Validasi

\begin{tabular}{ccc}
\hline & 0 & 1 \\
\hline 0 & 50 & 11 \\
\hline 1 & 14 & 41 \\
\hline
\end{tabular}

Tabel 3. Precision, Recall, fl-score, dan Support pada Data Validasi pada Model 1

\begin{tabular}{lcccc}
\hline & Precision & Recall & F1-score & Support \\
\hline $0($ Non $R D)$ & 0.78 & 0.82 & 0.80 & 61 \\
\hline $1($ RD $)$ & 0.79 & 0.75 & 0.77 & 55 \\
\hline Avg / total & 0.78 & 0.78 & 0.78 & 116 \\
\hline
\end{tabular}




\section{B. Standarisasi data}

Skenario pemodelan kedua adalah dengan melakukan standarisasi pada data. Standarisasi dilakukan dengan menggunakan class "StandardScaler" dari library scikit learn "sklearn.preprocessing". Standarisasi dilakukan pada atribut ciri dan tidak dilakukan pada label. Hasil yang didapatkan dari model 2 ini justru mengalami penurunan yang ditunjukkan pada Tabel 4 . Akurasi dari data pelatihan menjadi 68,37\%, akurasi pada data pengujian menjadi $67,85 \%$, dan akurasi dari data validasi menjadi $66,38 \%$. Confusion matrix dan analisis statistik secara berturut-turut ditunjukkan pada Tabel 5 dan 6.

\begin{tabular}{cccc} 
Tabel & 4. Performa Model 2 (standard scaler) \\
\hline Model & $\begin{array}{c}\text { Akurasi Data } \\
\text { Pelatihan }\end{array}$ & $\begin{array}{c}\text { Akurasi Data } \\
\text { Pengujian }\end{array}$ & $\begin{array}{c}\text { Akurasi Data } \\
\text { Validasi }\end{array}$ \\
\hline Model 2 & $68,37 \%$ & $67,85 \%$ & $66,38 \%$ \\
\hline
\end{tabular}

Tabel 5. Confusion matrix model 2 pada data validasi

\begin{tabular}{ccc}
\hline & 0 & 1 \\
\hline 0 & 37 & 24 \\
\hline 1 & 15 & 40 \\
\hline
\end{tabular}

Tabel 6. Precision, recall, f1-score, dan Support pada Data Validasi pada Model 2

\begin{tabular}{lcccc}
\hline & Precision & Recall & F1-score & Support \\
\hline $\begin{array}{l}\text { (Non } \\
R D)\end{array}$ & 0.71 & 0.61 & 0.65 & 61 \\
\hline $1(R D)$ & 0.62 & 0.73 & 0.67 & 55 \\
\hline Avg / total & 0.67 & 0.66 & 0.66 & 116 \\
\hline
\end{tabular}

\section{Feature selection}

Pada feature selection dilakukan seleksi pada feature (ciri) yang memiliki nilai korelasi positif terhadap variabel class atau target. Pada Gambar 3. terdapat nilai korelasi antar feature (ciri). Dari gambar tersebut terlihat bahwa terdapat 3 feature yang memiliki nilai negatif yaitu atribut 1,17 , dan 18 . Selanjutnya dilakukan pelatihan model dengan menghilangkan ketiga atribut tersebut. Hasilnya ditunjukkan pada Tabel 7, 8, dan 9 dimana terjadi kenaikan akurasi pada data pengujian dibandingkan dengan skenario pemodelan kedua.

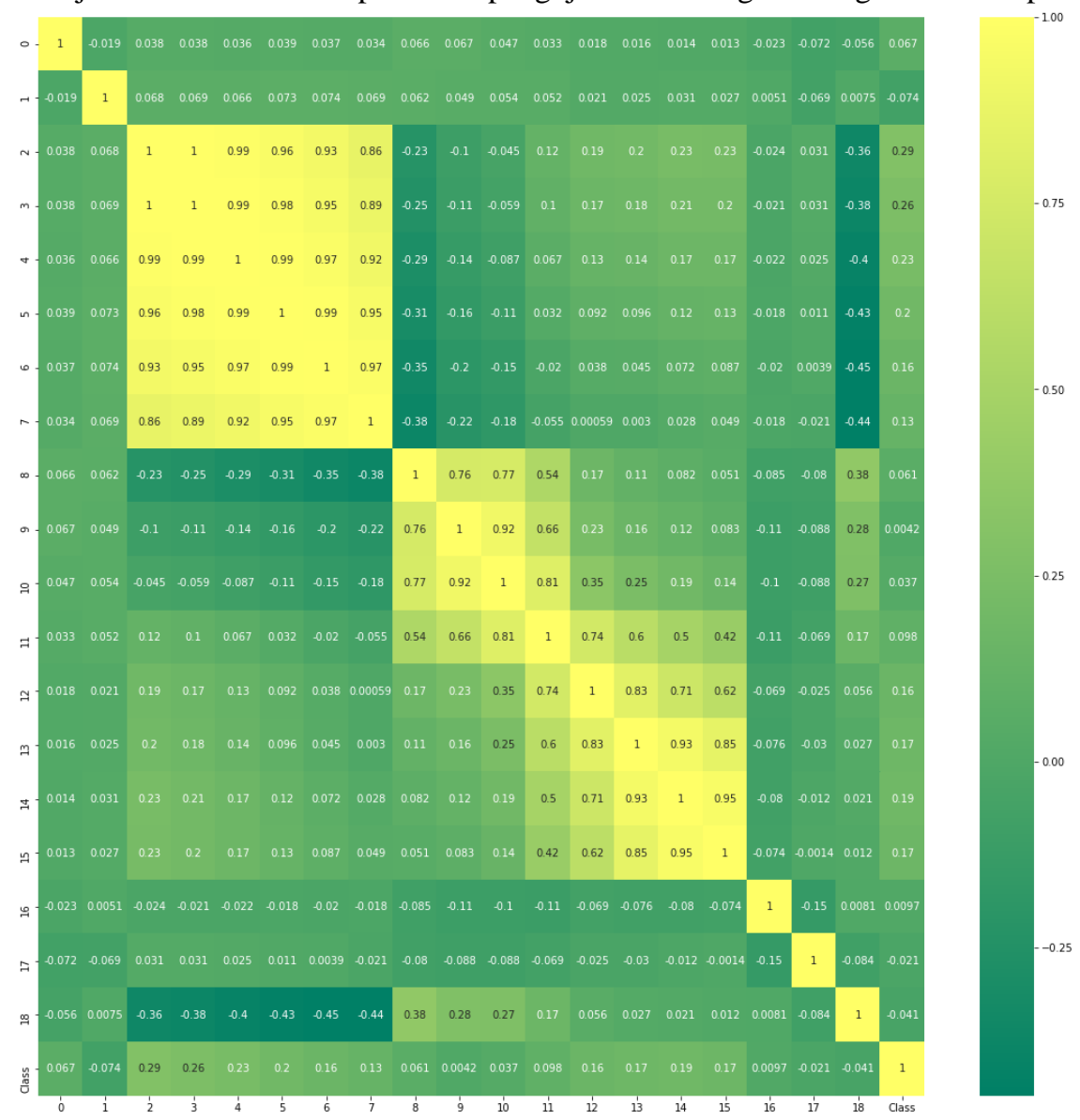

Gambar 3. Feature correlation 
Tabel 7. Performa Model 3 (feature selection)

\begin{tabular}{cccc}
\hline Model & $\begin{array}{c}\text { Akurasi } \\
\text { Train Data }\end{array}$ & $\begin{array}{c}\text { Akurasi } \\
\text { Test Data 1 }\end{array}$ & $\begin{array}{c}\text { Akurasi } \text { Test Data } \\
\mathbf{2}(\mathbf{1 0 \%} \text { dari total) }\end{array}$ \\
\hline Model 3 & $76,52 \%$ & $74,60 \%$ & $72,41 \%$ \\
\hline
\end{tabular}

Tabel 8. Confusion Matrix Model 3 pada Data Validasi

\begin{tabular}{ccc}
\hline & 0 & 1 \\
\hline 0 & 46 & 15 \\
\hline 1 & 17 & 38 \\
\hline
\end{tabular}

Tabel 9. Precision, Recall, fl-score, dan Support pada Data Validasi pada Model 3

\begin{tabular}{ccccc}
\hline & Precision & Recall & F1-score & Support \\
\hline$O($ Non $R D)$ & 0.73 & 0.75 & 0.74 & 61 \\
\hline $1(R D)$ & 0.72 & 0.69 & 0.70 & 55 \\
\hline Avg / total & 0.72 & 0.72 & 0.72 & 116 \\
\hline
\end{tabular}

\section{Hyper-parameter tuning}

Langkah terakhir yang dilakukan adalah dengan mencari parameter terbaik dari algoritma regresi logistik. Pencarian nilai parameter ini dilakukan pada parameter C, iterasi maksimal (max_iter), dan penalti. Nilai yang digunakan dalam pencarian nilai parameter terbaik dari setiap parameter ditunjukkan pada Tabel 10. Hyper-parameter tuning dilakukan dengan menggunakan metode Grid Search. Pada pencarian parameter terbaik dari model regresi logistik ini menggunakan pembagian data dengan metode cross validation dengan jumlah fold sebanyak 5 fold. Pencarian parameter terbaik dengan menggunakan metode Grid Search didapatkan hasil bahwa nilai $C$, max_iter, dan penalti terbaik dari masing-masing model memiliki nilai yang berbeda. Pada Tabel 11. terdapat parameter beserta nilainya dari masing-masing skenario model yang memberikan performa yang terbaik dari keseluruhan kombinasi nilai parameter. Nilai parameter pada masingmasing skenario tersebut menghasilkan model dengan performa yang terangkum pada Tabel 12 .

Tabel 10. Parameter

\begin{tabular}{ccc}
\hline $\boldsymbol{C}$ & Max_iter & Penalti \\
\hline $\begin{array}{c}\text { Log scale -4 sampai 4 dengan } \\
\text { step 20 }\end{array}$ & 100, 200, 500, 1000 & 11,12 \\
\hline
\end{tabular}

Tabel 11. Nilai Parameter Terbaik pada Masing-Masing Model

\begin{tabular}{cccc}
\hline Model & C & Max_iter & Penalti \\
\hline Model 1 & 11,288 & 200 & 11 \\
\hline Model 2 & 29,763 & 100 & 11 \\
\hline Model 3 & 11,288 & 200 & 12 \\
\hline
\end{tabular}

Tabel 12. Tabel Performa dari hasil hyperparameter tuning

\begin{tabular}{cccc}
\hline Model & $\begin{array}{c}\text { Akurasi Data } \\
\text { Pelatihan }\end{array}$ & $\begin{array}{c}\text { Akurasi Data } \\
\text { Pengujian }\end{array}$ & $\begin{array}{c}\text { Akurasi Data } \\
\text { Validasi }\end{array}$ \\
\hline Model 1 & $76,10 \%$ & $74,28 \%$ & $80,17 \%$ \\
\hline Model 2 & $75,83 \%$ & $72,03 \%$ & $75 \%$ \\
\hline Model 3 & $75,28 \%$ & $75,56 \%$ & $74,14 \%$ \\
\hline
\end{tabular}

\section{Kesimpulan}

Berdasarkan hasil pemodelan yang dilakukan dengan menggunakan tiga skenario pemodelan didapatkan hasil yang berbeda dari masing-masing skenario pemodelan. Pada skenario pemodelan pertama menghasilkan rata-rata nilai akurasi pada data pelatihan, data pengujian, dan data validasi yang lebih baik dari skenario pemodelan kedua dan ketiga. Nilai akurasi yang didapatkan dari hasil pengujian pada data pelatihan, pengujian, dan validasi pada skenario pemodelan pertama adalah berturut-turut sebesar 75,96\%,75,24\%, dan $78,45 \%$. Setelah menerapkan hyperparameter tuning menghasilkan model dengan performa lebih baik. Model yang memiliki performa terbaik adalah model 1 dari skenario pemodelan pertama. Nilai akurasi yang didapatkan dari hasil pengujian pada data pelatihan, pengujian, dan validasi pada model ini adalah berturutturut sebesar 76,10\%, 74,28\%, dan 80,17\%.

\section{Daftar Pustaka}

[1] Y. Yuhelma, Y. Hasneli I, and F. Annis N, "Identifikasi dan Analisis Komplikasi Makrovaskuler dan Mikrovaskuler pada Pasien Diabetes Mellitus," J. Online Mhs., vol. 2, no. 1, pp. 569-579, 2015.

[2] R. Casanova, S. Saldana, E. Y. Chew, R. P. Danis, C. M. Greven, and W. T. Ambrosius, "Application of random forests methods to diabetic retinopathy classification analyses," PLoS One, vol. 9, no. 6, pp. 
1-8, 2014, doi: 10.1371/journal.pone.0098587.

[3] P. Soewondo, S. Soegondo, K. Suastika, A. Pranoto, D. W. Soeatmadji, and A. Tjokroprawiro, "Medical journal of Indonesia," Med. J. Indones., vol. 19, no. 4, pp. 235-44, 2010, [Online]. Available: http://mji.ui.ac.id/journal/index.php/mji/article/view/412/404.

[4] G. T. Reddy et al., "An ensemble based machine learning model for diabetic retinopathy classification," in 2020 International Conference on Emerging Trends in Information Technology and Engineering (ic-ETITE), 2020, pp. 1-6.

[5] E. Christodoulou, J. Ma, G. S. Collins, E. W. Steyerberg, J. Y. Verbakel, and B. Van Calster, "A systematic review shows no performance benefit of machine learning over logistic regression for clinical prediction models," J. Clin. Epidemiol., vol. 110, pp. 12-22, 2019, doi: 10.1016/j.jclinepi.2019.02.004.

[6] Y. F. Kao and R. Venkatachalam, "Human and Machine Learning," Comput. Econ., no. February, pp. 1-21, 2018, doi: 10.1007/s10614-018-9803-z.

[7] G. F. Cooper et al., "An evaluation of machine-learning methods for predicting pneumonia mortality," Artif. Intell. Med., vol. 9, no. 2, pp. 107-138, 1997, doi: 10.1016/S0933-3657(96)00367-3.

[8] T. Sasakawa, J. Hu, and K. Hirasawa, "A brainlike learning system with supervised, unsupervised, and reinforcement learning," Electr. Eng. Japan, vol. 162, no. 1, pp. 32-39, 2008.

[9] G. Varoquaux, L. Buitinck, G. Louppe, O. Grisel, F. Pedregosa, and A. Mueller, "Scikit-learn: machine learning without learning the machinery," GetMobile Mob. Comput. Commun., vol. 19, no. 1, pp. 2933, 2015, doi: 10.1145/2786984.2786995.

[10] B. Antal and A. Hajdu, "Diabetic Retinopathy Debrecen Data Set," UCI Mach. Learn. Repos., 2014.

[11] S. Mohammadian, A. Karsaz, and Y. M. Roshan, "A comparative analysis of classification algorithms in diabetic retinopathy screening," Proc. Int. Conf. Softw. Eng. Knowl. Eng. SEKE, vol. 60, no. 10, p. 631, 2017, doi: 10.18293/SEKE2017-207.

[12] G. Luo, "A review of automatic selection methods for machine learning algorithms and hyperparameter values," Netw. Model. Anal. Heal. Informatics Bioinforma., vol. 5, no. 1, pp. 1-15, 2016, doi: 10.1007/s13721-016-0125-6.

[13] G. King and L. Zeng, "Logistic regression in rare events data," Polit. Anal., vol. 9, no. 2, pp. 137-163, 2001.

[14] S. C. Bagley, H. White, and B. A. Golomb, "Logistic regression in the medical literature: Standards for use and reporting, with particular attention to one medical domain," J. Clin. Epidemiol., vol. 54, no. 10, pp. 979-985, 2001, doi: 10.1016/S0895-4356(01)00372-9.

[15] C. Y. J. Peng, K. L. Lee, and G. M. Ingersoll, “An introduction to logistic regression analysis and reporting," J. Educ. Res., vol. 96, no. 1, pp. 3-14, 2002, doi: 10.1080/00220670209598786. 